\title{
RELACIONES SINTÁCTICAS EN LA ZONA ADVERBIAL: EL CASO DE PUES
}

\author{
MARIANA MORÓN USANDIVARAS \\ Universidad de Buenos Aires \\ marianamoron@filo.uba.ar
}

\section{RESUMEN}

En el marco propuesto por Borzi (2001 y 2010), sostenemos que los esquemas binarios de coordinación/subordinación (definidos a priori y cuyas limitaciones se aspira a resolver por medio del concepto de interordinación) no son pertinentes para dar cuenta de la relación existente en el período causal porque esta es el resultado de los grados de coherencia/continuidad discursiva existente entre las cláusulas que lo conforman.

El presente artículo propone estudiar el tipo de relación sintáctica que se establece entre las cláusulas causales introducidas por pues y la otra cláusula del período en el discurso alberdiano en relación con los siguientes parámetros: a) continuidad tópica entre los conectados del período causal, b) distribución de la información, c) iconicidad del orden de las cláusulas respecto del orden de los hechos y d) función retórica de ambas cláusulas.

PALABRAS CLAVE: Lingüística Cognitiva, cláusulas adverbiales impropias, cláusulas causales, pues, subordinación, coordinación.

\section{SYNTACTICAL RELATIONSHIP IN ADVERBIAL CLAUSES: THE PUES CONNECTOR}

\section{ABSTRACT}

Within the framework proposed by Borzi (2001 and 2010), we argue that coordination/subordination binary schemes (defined a priori and whose deficiencies the concept of interordination attempts to resolve) are not pertinent to attest the existing relationship in the causal period because this is the result of the degrees of discursive coherence/continuity that exist between the clauses that constitute it.

The present article proposes to study the type of syntactical relationship that is established between causal clauses introduced by pues (then) and the other clause of the period in Alberdi's discourse in relation to the following parameters: a) topic continuity between the connected clauses, b) information distribution, c) iconicity of the order of the clauses in relation to the order of the facts and d) rhetoric function of both clauses.

KEY WORDS: Cognitive Grammar, Adverbial clauses, Causal clauses, pues, subordination, coordination.

\section{INTRODUCCIÓN}

En este artículo se presenta una aproximación al estudio de las relaciones sintácticas en la zona adverbial causal, a partir de la observación del tipo de relación sintáctica que establecen las cláusulas causales introducidas por pues 
con la otra cláusula del período causal. Con este fin, se realizará un análisis cualitativo y cuantitativo del uso de pues en el discurso alberdiano. ${ }^{1}$

En el marco propuesto por Borzi (1999 y 2001), sostenemos que las conexiones adverbiales tienen, en principio, carácter discursivo y que las relaciones pragmáticas, semánticas y sintácticas que pueden asignar las cláusulas de los períodos que integran son el resultado de los grados de coherencia existente entre estas. Consideramos, asimismo, que las relaciones sintácticas de subordinación de actante, coordinación y centro-periferia son el resultado de la acumulación de distintos atributos contextuales y están ordenadas en un continuum ordenado, pero no discreto.

El trabajo se divide en cinco apartados. En el primero, se exponen algunos de los presupuestos fundamentales del marco teórico utilizado. En el segundo, se presenta un breve panorama de los estudios gramaticales realizados hasta este momento sobre las relaciones sintácticas en la oración compuesta y sobre el uso del conector causal pues. A continuación, en el tercer apartado, se explica la metodología utilizada. Luego, en el apartado 4, se realiza un análisis cualitativo y cuantitativo del uso de pues en De la anarquía en relación con los siguientes parámetros: a) continuidad tópica entre los conectados, b) distribución de la información, c) iconicidad del orden de las cláusulas respecto del orden de los hechos y d) función retórica de las cláusulas. Por último, en el apartado 5, se enuncian las conclusiones.

\section{MARCO TEÓRICO}

\subsection{Enfoque Cognitivo Prototípico}

El presente trabajo se asienta sobre dos presupuestos teóricos del Enfoque Cognitivo Prototípico (ECP): a) la concepción del signo motivado por el contexto discursivo y por el objetivo comunicativo del hablante, b) el concepto de categoría que surge a partir de la Teoría de los Prototipos.

Con respecto al primer presupuesto, desde el ECP se concibe que la gramática es un sistema de signos, pero no un sistema autónomo e independiente localizado en la mente de los individuos y previo a su utilización en un discurso determinado, sino como un conjunto de rutinas recurrentes de uso, cuyo estatus es constantemente renegociado en el habla y en la escritura en

1 Juan Bautista Alberdi (Tucumán, 1810 - París, 1884). Político, jurisconsulto y escritor argentino. Residió desde muy joven en Buenos Aires, ciudad en la que desarrolló una importante actividad política, cultural y social. Decidido opositor al gobierno de Juan Manuel de Rosas, debió expatriarse y pasó casi toda su vida en el exilio. En 1852, escribió una de sus obras más importantes: Bases y puntos de partida para la organización política de la República Argentina, texto que sirvió de base para la Constitución Argentina de 1853. 
cada situación comunicativa. ${ }^{2}$ Es la función comunicativa la que estructura la gramática de una lengua.

En el ECP, el análisis está orientado al contexto; la búsqueda de motivación de las ocurrencias lingüísticas no se limita a la oración sino que tiene en cuenta fines comunicativos del texto en todos los niveles. Como sostiene la Escuela de Columbia (Diver 1995: §1.1), la comunicación siempre se produce en un contexto y las formas lingüísticas utilizadas por los hablantes o escritores no pueden ser entendidas fuera de la relación a ese contexto. La elección de determinada forma depende de lo que el hablante quiere lograr en un contexto determinado y es siempre significativa; el signo está motivado por la intención comunicativa del hablante y por el contexto situacional.

En cuanto al segundo presupuesto, el ECP considera que las categorías lingüísticas no son autónomas respecto de la organización conceptual general. El lenguaje no constituye una capacidad cognitiva separada de las demás, sino que se relaciona directamente con otros procesos cognitivos como desplazarse entre objetos o tocar un instrumento musical. La habilidad humana para comparar objetos y situaciones y registrar las diferencias entre ellos es fundamental en el proceso de categorización y en la estructuración de la experiencia (Langacker 1987).

Desde una perspectiva tradicional, se concibe que los miembros de una categoría se agrupan porque comparten características que son consideradas condiciones necesarias y suficientes para pertenecer a dicha categoría. En otras palabras, todos los miembros comparten el mismo estatus dentro de esa categoría. Sin negar esta posibilidad, la Teoría de los Prototipos profundiza un poco más su estudio. Para esta, algunas categorías presentan gradaciones entre sus miembros, miembros centrales y, además, límites borrosos. Otras categorías tienen límites claros, pero manifiestan efectos prototípicos, es decir, algunos miembros son considerados mejores ejemplos que otros. Las categorías no están organizadas únicamente en términos de taxonomías jerárquicas. ${ }^{3}$ "Las categorías se ven dotadas de una organización interna, con un foco ocupado por los ejemplares más representativos y una periferia indeterminada, donde cabe mayor heterogeneidad" (Moure 1994: 186).

2 "The notion of Emergent Grammar is meant to suggest that structure, or regularity, comes out of discourse and is shaped by discourse in an ongoing process. Grammar is, in this view, simply the name of certain categories of observed repetitions in discourse. It is hence not to be understood as a prerequisite for discourse, a prior possession attributable in identical form to both speaker and hearer. Its forms are not fixed templates but emerges out face-to-face interaction in ways that reflect the individual speaker's past experience of these forms, and their assessment of the present context, including especially their interlocutors, whose experience and assessments may be quite different" (Hopper 1998: 156).

${ }^{3}$ Cf. Rosh (1978: 31-43), Lakoff (1987: §2), Moure (1994: §§ 4 y 5.3). 


\subsection{Las relaciones sintácticas entre las cláusulas}

En el marco propuesto por Borzi (1999 y 2001), afirmamos que las conexiones adverbiales tienen, en principio, carácter discursivo y que las relaciones sintácticas entre las cláusulas son el resultado de los grados de coherencia existentes entre estas. Consideramos además que los esquemas binarios de coordinación/subordinación (definidos a priori y cuyas limitaciones se aspira a resolver por medio del concepto de interordinación) no son suficientes para dar cuenta de la relación existente en el período causal porque esta es resultado de los grados de coherencia/continuidad discursiva existente entre cláusulas (cf. §2.1). Dado que sostenemos que las relaciones sintácticas de coordinación y de subordinación reflejan la continuidad del discurso entre cláusulas y que la continuidad es una cuestión de grados, se sostiene que las relaciones pragmáticas, semánticas y sintácticas se inscriben en un continuum ordenado y no discreto. Coherentemente con lo reseñado en el apartado anterior, postulamos que las relaciones sintácticas y las categorías sintácticas son el producto de una combinatoria de atributos y sus elementos manifiestan distintos grados de prototipicidad.

\section{ESTADO DE LA CUESTIÓN}

Los estudiosos de la lengua española han asignado diferentes tipos de relaciones sintácticas, semánticas y/o pragmáticas a la combinación de cláusulas, entre las que podemos nombrar la coordinación, la subordinación, cosubordinación, la interordinación y la relación de centro-periferia.

En lo que se refiere a la coordinación, puede definirse como "el procedimiento gramatical que se usa para asociar constituyentes sintácticos sin establecer una jerarquía entre ellos" (Camacho 1999[2000]: 2637). Esta asociación se realiza a través de conjunciones que manifiestan diferentes tipos de relaciones semánticas: copulativa, disyuntiva, adversativa, causal y consecutiva. Muchos gramáticos (Gili Gaya 2000[1943]; el Esbozo 1981[1973]; Alarcos 1994; Di Tullio 1997; Verstraete 2008 y NGLE 2009, entre otros) establecen una oposición entre la coordinación y la subordinación. En palabras de la Academia:

La diferencia esencial entre coordinación y subordinación puede resumirse del modo siguiente: las oraciones coordinadas se enlazan en el período y expresan relaciones variadas entre sí; pero no se funden hasta el punto de que una de ellas pase a ser elemento sintáctico de la otra. [...] Las subordinadas en cambio son elementos incorporados formalmente a la oración principal o subordinante, como sujeto, predicado o complemento de cualquier clase (Esbozo 1973[1981]: 503).

Aquí se advierte que la definición del Esbozo sigue, como ocurre en otros autores tales como Gili Gaya (2000[1943]), Alarcos (1994) o Seco (1999), un punto de vista sintáctico y de conmutación del llenado de una función por otro en la subordinación (La que habla es mi amiga/Ella es mi amiga, por ejemplo). 
Mientras que la coordinación queda definida por la identidad o equivalencia sintáctica de los conectados.

En cuanto a la co-subordinación, Lapesa (1978) considera que en algunas oraciones causales:

el miembro causal es independiente del otro miembro, pero no está ligado por coordinación. Ambos están subordinados a un verbo implícito de declaración, interrogación, mandato, voluntad o afecto, representativo del acto lingüístico de emitir el mensaje con la modalidad correspondiente a cada caso. [...] La independencia mutua entre las dos sub-oraciones ha inducido a considerarlas coordinadas, pero en realidad son co-subordinadas heterogéneas, con distinta función cada una: objeto directo o sujeto la no causal; complementaria circunstancial, la de causa (Lapesa 1978: 203).

Aunque esta propuesta es novedosa e implica un tratamiento diferente de la relaciones intercláusulas en las denominadas subordinadas adverbiales, el concepto de co-subordinación no deja en claro cuál es la relación entre la cláusula causal y la otra cláusula del período, que funciona semánticamente como su consecuencia o efecto.

En lo que respecta a la interordinación, Rojo (1978) propone la existencia de oraciones bipolares que "son las constituidas inmediatamente por dos cláusulas que mantienen entre sí una relación de interordinación" (Rojo 1978: 126), es decir, una relación de interdependencia entre dos cláusulas que se presuponen mutuamente. Pertenecen a este último grupo las condicionales, las causales, las concesivas, las consecutivas y las adversativas. Rojo diferencia la bipolaridad de la coordinación en que los miembros de una relación de coordinación presentan paralelismo funcional, mientras las cláusulas de una oración bipolar, en cambio, no pueden ser más que dos y cada una presenta una función bien determinada. La interordinación también se distingue de la subordinación en que ninguna de las cláusulas forma parte de la otra. El aporte de Rojo es establecer una nueva relación, la interordinación, que entra en juego con la coordinación y la subordinación sin ser parte de ninguna de ellas.

Por su parte, Borzi (2001 y 2010) reconoce tres tipos de relaciones sintácticas interclausales que van de un mayor grado de imbricación entre las cláusulas a uno menor. Hipotéticamente ubicadas en un continuum en forma de ojiva, en el extremo izquierdo se encuentra la subordinación de actante, en el otro extremo la subordinación retórica o centro-periferia y en el centro, en la zona donde confluyen ambos arcos, la coordinación. En términos situacionales, la subordinación de actante es utilizada por los hablantes para referirse a eventos no simétricos donde lo importante es un evento, no la secuencia. Las cláusulas comparten tema y función retórica, el evento de una de las cláusulas es parte del evento de la otra y el orden de las cláusulas refleja relativamente el orden de los hechos. La información vieja está en la cláusula introducida por un encabezador y esta es la cláusula que se describe como 'subordinada'. La información nueva está en la cláusula que se describe como 'principal'. Por su parte, los hablantes utilizan la coordinación para designar hechos simétricos, 
donde lo importante son los eventos en sí y además la secuencia. El orden de las cláusulas es icónico respecto del orden de los hechos designados y en ambas cláusulas se presenta información nueva. Las cláusulas presentan continuidad tópica relativa, identidad o alta conexión entre los eventos, y ambas pertenecen a una misma función retórica. $\mathrm{Y}$, en el otro extremo de la ojiva, el hablante usa la relación centro-periferia cuando lo más importante no son los eventos sino la función que el hablante establece entre las cláusulas que designan eventos en el discurso. El objetivo del hablante es presentar dos cláusulas con distinto objetivo comunicativo o distinta función retórica. El orden de las cláusulas no refleja necesariamente el orden de los hechos designados. ${ }^{4}$

A propósito de las cláusulas causales introducidas por pues, los gramáticos de la lengua española no concuerdan en el tipo de relación sintáctica que establece con la otra cláusula del período causal. Algunos lo ubican en el ámbito de la coordinación (GRAE 1931; Alcina Franch y Blecua 1991[1975]; Portolés 1989, López García 1994; Goethals 2002); otros en el de la subordinación (Gili Gaya 2000[1943]; Esbozo 1981[1973]; Alarcos 1994; Galán Rodríguez 2000[1999]; Gutiérrez O. 2000; NGLE 2009) o co-subordinación (Lapesa 1978). Una vez clasificada la cláusula causal como subordinada, tampoco coinciden en si pertenece a la subordinación sustantiva (Gili Gaya) o a la adverbial (Alarcos).

Desde el Enfoque Cognitivo Prototípico esperamos poder ofrecer una respuesta a esta problemática, porque partimos de una sintaxis motivada por la intención comunicativa del hablante. Por ende, cada estructura sintáctica es estudiada en relación con su significado en el discurso y en la situación comunicativa en la que es producida. En nuestro caso, el análisis se basa en el estudio cualitativo y cuantitativo de los fenómenos contextuales que motivan las construcciones causales de pues en el discurso alberdiano.

\section{CORPUS Y METODOLOGÍA}

El corpus está conformado por 361 cláusulas de pues con valor causal encontradas en trece obras de J.B. Alberdi: 1) La edición genética que he realizado de De la anarquía y sus dos causas principales, del gobiernos y sus dos elementos necesarios con motivo de su reorganización por Buenos Aires; 2) la edición genética de El crimen de la guerra realizada por Lois en 2007; 3) Fragmento preliminar al estudio del derecho (1937); 4) Bases y punto de partida para la organización política de la Confederación Argentina (1952); 5) Sistema económico y rentístico para la Confederacion Argentina segun sus Constitución de 1953 (1854); 6) Elementos del derecho público provincial argentino (1853); 7) De la integridad nacional de la República Argentina, bajo todos sus sistemas de gobierno, á propósito de sus tratados domésticos con Buenos Aires (1855); 8) Peregrinación de Luz del Día (1871); 9) La república argentina consolidada en 1880 con la ciudad de Buenos Aires por capital

\footnotetext{
${ }^{4}$ La relación centro-periferia presenta puntos de contacto con la noción de subordinación núcleosatélite de Matthiessen y Thompson (1988).
} 
(1881); dos artículos escritos bajo el seudónimo de Figarillo en 1838: 10) "Reacción contra el Españolismo" y 11) "La generación presente a la faz de la generación pasada"; dos ensayos: 12) "Ideas para presidir la confección de un curso de filosofía contemporáneo" y 13) "La omnipotencia del estado es la negación de la libertad individual".

En el presente trabajo se realizará un análisis cualitativo y cuantitativo de los períodos causales en el que interviene pues en relación con los siguientes atributos contextuales: a) distribución de la información entre las cláusulas, b) continuidad tópica entre los conectados, c) función retórica de cada cláusula y d) posición de las cláusulas e iconicidad del orden de las cláusulas respecto del orden de los hechos.

a) Distribución de la información entre las cláusulas ${ }^{5}$

La información presentada en cada cláusula puede ser presentada como conocida o nueva para el hablante. Entendemos por información conocida aquella que ha sido mencionada previamente en el discurso, puede inferirse del contexto discursivo previo o de la situación comunicativa o ser compartida entre hablante y oyente por saber enciclopédico o experiencia común. Se considera nueva aquella información que es mencionada por primera vez en el discurso y no reformula una idea anterior, que no puede ser inferida o presupuesta del contexto lingüístico previo o de la situación comunicativa y que no es compartida ni por conocimiento enciclopédico ni por experiencia común (Morón Usandivaras 2012).

En (1), ofrecemos un ejemplo de información conocida porque ha sido mencionada anteriormente en el discurso.

(1) La aduana ó su renta es nacional, no solamente porque la ley lo dice, sinó porque sale del bolsilillo de los argentinos. Ellos pagan esa contribución en el puerto de Buenos Aires, por ser el puerto por donde hoy hacen todo el tráfico de sus importaciones y exportaciones. No hay necesidad de federalizar ó nacionalizar la aduana de Buenos Aires: ella es nacional por su naturaleza económica; es nacional, (porque se forma de la contribubucion que toda la Nacion pạgạ en esenpuerto) (Alberdi 1862: 3).

En (1), la información que introduce la cláusula de porque (entre paréntesis) ha sido mencionada en las oraciones y cláusulas anteriores. Esto puede comprobarse si se presta atención a los distintos tipos de subrayados. En subrayado simple puede apreciarse que el sujeto de la cláusula causal que se manifiesta en el pronombre personal de $3^{0}$ persona y en la desinencia del verbo 'formar' se encuentra repetido con distintos recursos gramaticales en tres ocasiones anteriores: 'La aduana o su renta', 'la aduana de Buenos Aires', 'ella'.

En subrayado doble se encuentran 'los argentinos', 'ellos' y 'toda la Nación' acompañando a los verbos o grupos verbales (subrayados con puntos)

\footnotetext{
${ }^{5}$ Cf., por ejemplo, Borzi (1994 y 1998) y Daneš (1974).
} 
'sale del bolsillo' 'pagan' y 'paga'; el hablante presenta en tres oportunidades la misma situación expresada de igual o similar manera. También se repite: 'esa contribución' y 'la contribución' (en subrayado entrecortado). El locativo (subrayado viborita) es el mismo que el de la oración anterior: 'en el puerto de Buenos Aires', 'ese puerto'.

(2) La aduana argentina de Buenos Aires forma casi todo el tesoro de la Nacion, (pues es la contribucion que ha reemplazado á todas las de régimen colonial, mediante el desarrollo del comercio debido al nuevo régimen) (Alberdi 1862: 5-6).

La causal de (2), por su parte, es un ejemplo de información nueva. En realidad, en ambas cláusulas del período causal se presenta información nueva. Es la primera vez que Alberdi menciona que la aduana argentina de Buenos Aires forma el tesoro de la nación, tema recurrente del ensayo. Considero que la segunda cláusula (entre paréntesis) introduce información nueva porque es una información que no creo que hayan conocido todos los contemporáneos y posibles lectores de Alberdi, aunque sí algunos de los destinatarios del ensayo.

b) Continuidad tópica entre los conectados del período causal

Entendemos por continuidad tópica la presencia recurrente o continua de uno o más elementos en el discurso.

In terms of the clause-level topic continuity, we deal with the speaker's judgments as to how easy/difficult it is for the hearer to identify uniquely the topic NP. Pronouns, anaphora, definite markers, demonstrative and other topic-marking particles or construction/devices are in general and also in UTE, the grammatical means by which the speaker attempts to make sure that the hearer can follow the clause-level topic NP, or known "what the information in the clause is about (Givón 1980: 302-303).

Si bien nuestra propuesta parte de la realizada por Givón (1980) y Bentivoglio (1983) para describir las estrategias gramaticales que el hablante utiliza para mantener presente en el discurso el nominal que funciona como tópico o tema, ampliamos el espectro a todos los designados que se encuentren en las cláusulas causales bajo estudio. Por otro lado, restringimos, en este momento, la continuidad tópica a la que se establece entre los conectados del período causal y no al análisis de todo el discurso.

A modo de ejemplo, se analizan las oraciones (3) y (4).

(3) Cuando entró a su casa, Juan escuchó la voz de su mamá.

(4) Si ganan este partido, iré a la final.

En (3) hay identidad de actante sujeto; las dos cláusulas comparten el mismo sujeto: Juan entró y Juan escuchó. También comparten el actante locativo (la casa) y el actante temporal; las acciones son simultáneas. Todos ellos son índices de una alta continuidad tópica entre los conectados. En cambio, (4) es un ejemplo de baja continuidad tópica. No hay identidad de actante sujeto: ellos 
vs. yo. Tampoco comparten el actante locativo o el temporal (presente vs. futuro).

La subordinación de actante es la relación que se caracteriza por una alta continuidad entre sus conectados, la coordinación presenta una continuidad media mientras la relación centro-periferia, al ser una relación más laxa, tiende a manifestar baja continuidad tópica entre sus miembros.

c) Función retórica de cada cláusula

Otro parámetro a tener en cuenta para distinguir la relación sintáctica entre los conectados es la función retórica de las cláusulas. Por función retórica se entiende la intención comunicativa que manifiesta el hablante en cada cláusula o fragmento conectado: afirmar, hipotetizar, preguntar, exhortar, aconsejar, expresar un deseo o un sentimiento, explicar, etc. A continuación mediremos cuál es la intención comunicativa del escritor en cada cláusula del período causal. Si las dos cláusulas comparten la misma función retórica, consideramos que estamos ante un solo acto de habla mientras que, si las cláusulas presentan distintas intenciones, nos encontramos ante dos actos de habla diferentes. Cuando hay distinto acto de habla, los dos actos de habla dan cuenta de la fuerte intervención del hablante en el mensaje que está estableciendo algún tipo de relación entre ambas cláusulas.

(5) ¡A Apúrate!, que llegamos tarde.

(6) Cuando llegamos, la fiesta ya había terminado.

El ejemplo (5) presenta dos funciones retóricas distintas; la primera es una exhortación (apúrate) y la segunda es una justificación de esa exhortación; la presencia del hablante se hace evidente. En (6) ambas cláusulas manifiestan la misma intención comunicativa de contar o relatar un hecho. En este último caso, la presencia del hablante pareciera diluirse tras los hechos narrados.

d) Posición de las cláusulas e iconicidad del orden de las cláusulas respecto del orden de los hechos

Consideramos que hay iconicidad del orden de las cláusulas respecto del orden de los hechos, cuando el orden de las cláusulas respeta el orden temporal en el que transcurren los hechos. Esta iconicidad se rompe cuando se invierte ese orden temporal, es decir, cuando el hecho que se encuentra en la cláusula prepuesta es temporalmente posterior al que se halla en la pospuesta. La relación causa-consecuencia implica que la causa es anterior a su consecuencia. El orden de las cláusulas será icónico cuando el hablante presente la causa en la primera cláusula y la consecuencia en la segunda; el orden será no-icónico cuando la consecuencia se encuentre en la antepuesta y la causa en la pospuesta. La presencia del hablante también se manifiesta en la manera de presentar los eventos. Cuando el orden de las cláusulas respeta la iconicidad de 
los hechos representados y el contexto es más narrativo, pareciera que la voz del hablante se diluye tras los hechos; por el contrario, cuando el orden de las cláusulas rompe con la iconicidad, la intervención del hablante se evidencia con mayor claridad. Por ejemplo:

(7) Estudió todo el verano y aprobó.

(8) Aprobó porque estudió todo el verano.

En la oración (7), el orden de las cláusulas respeta el orden icónico de los hechos: primero se estudia y luego se aprueba. Por el contrario, en (8) el orden de las cláusulas es no icónico porque la primera cláusula presenta la consecuencia (aprobar) que es temporalmente posterior a la causa (estudiar). La ruptura de la iconicidad es un índice de la fuerte intervención del hablante; su presencia se hace visible puesto que los hechos están presentados en un orden que no coincide con la secuencia temporal y es el hablante el que ha establecido una determinada relación entre ellos.

\section{ANÁlisis DEL CORPUS}

A continuación se procede a analizar tres ejemplos de nuestro corpus en relación con los parámetros propuestos más arriba (continuidad tópica entre los conectados, distribución de la información, iconicidad del orden de las cláusulas respecto del orden de los hechos y función retórica de cada cláusula).

(9) La Nacion debera esas sumas. La Nacion existe; se conforma de todas las provincias inclusa $\mathrm{B}^{\mathrm{s}} \mathrm{A}^{\mathrm{s}}$. (Tiene tesoro pues paga contribuciones). Alguien lo administra y debe responder con el y con el credito publico fundado en él (Alberdi 1862: 2B19). ${ }^{6}$

En (9), encontramos que las dos cláusulas del período causal (entre paréntesis) presentan: a) identidad del actante sujeto: La Nación, manifestada en la desinencia de tercera persona del singular de los verbos 'tiene' y 'paga'; b) identidad de tiempo y modo verbal: los verbos de los conectados se encuentran en presente de indicativo y c) identidad de lugar: el territorio argentino. Atributos que dan cuenta de una alta continuidad tópica.

Por otro lado, la cláusula causal de pues ocupa la posición pospuesta y, por lo tanto, se rompe con el orden icónico de los hechos. Contra la expectativa de que la información nueva se encuentre en la cláusula pospuesta, la causal en este caso, la información nueva se presenta en la primera cláusula y la información conocida en la segunda. En el contexto discursivo previo, Alberdi explica cuáles son las contribuciones que realiza la Nación y cómo las paga. La información nueva y destacada es la que se encuentra en la cláusulaconsecuencia. Es esta información ("La Nación tiene tesoro") la que se recupera a la derecha en el discurso; se manifiesta en los pronombres personales

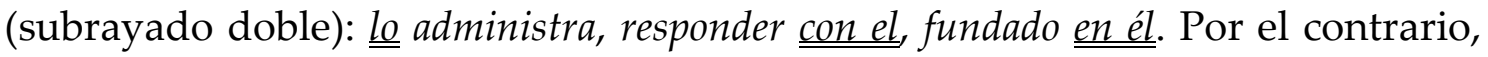

\footnotetext{
${ }^{6}$ Segundo Borrador de la edición genética de De la anarquía, folio 19.
} 
el ámbito de influencia de la causal es hacia la izquierda; explica la afirmación realizada en la primera cláusula. Esto se encuentra estrechamente relacionado con la función retórica de cada cláusula: la primera es la enunciación de un hecho, que se está poniendo en relevancia, mientras la segunda es una explicación de esa enunciación, la sostiene. ${ }^{7}$

(10) EI crédito ó la deuda de Buenos Aires puede ser nacionalizado de un modo por el cual la Nacion se convierta en deudora de la Provincia de Buenos Aires, sin dejar por eso de entregar sus recursos efectivos para aumentar la garantía del crédito provincial de Buenos Aires. Tal es lo que sucederia si las Provincias recibiesen el papel moneda de Buenos Aires, á título de préstamo ó de participacion del tesoro comun. Considerado como valor y prescindiendo de su calidad, la Nacion recibiria en préstamo lo que es suyo. (En su calidad de papel de deuda provincial, la Nacion recibiendo ese papel se constituiria prestamista de Buenos Aires, pues todo el que recibe papel de deuda pública, por algún valor que da en cambio, es prestamista de ese valor al Gobierno que ha emitido el papel) (Alberdi 1862: 72).

En (10), las dos cláusulas del período causal (entre paréntesis) presentan una relación parte-todo: a) el sujeto de una cláusula es parte del sujeto de la otra cláusula: La Nación es parte del pronombre indefinido todo; b) el lugar de la primera es parte del de la segunda: La Nación se encuentra en territorio argentino y el territorio argentino se encuentra en el mundo, es parte de ese lugar indefinido que implica la existencia de una ley de carácter universal. Los tiempos y aspectos verbales son diferentes: la primera cláusula (subrayada) es en sí misma un período condicional con su prótasis y apódosis (gerundiocondicional simple); ${ }^{8}$ la causal está en presente de indicativo, presente con valor de ley o máxima. Esta relación parte-todo es índice de una alta continuidad entre los conectados.

Como en el mensaje de (9), el orden de los hechos no es icónico; la intervención del hablante es evidente. En cuanto a la distribución de la información, la información nueva se presenta en la primera cláusula mientras la conocida está en la segunda; lo que allí se enuncia es una ley de carácter general o "universal". La intención comunicativa de Alberdi al utilizar una ley es, en primera instancia, explicar lo dicho anteriormente pero, sobre todo, busca sostener la tesis planteada en la cláusula-consecuencia y toda la relación causal en una ley inapelable.

(11) (Si Bss $\mathrm{A}^{\mathrm{s}}$. lo depuso [al gobierno nacional] ${ }^{9}$ no será $\mathrm{B}^{\mathrm{s}} \mathrm{A}^{\mathrm{s}}$. quien lo reponga, pues la esperiencia ha demostrado que el interes conque lo dispuso fue mas de su pueblo que el de la nacion).

\footnotetext{
${ }^{7}$ En un trabajo anterior propongo que pues es un conector sostén porque su función es precisamente sostener, explicar o justificar lo dicho en la cláusula anterior (cf. Morón Usandivaras 2010).

${ }^{8}$ Con respecto al uso del gerundio con valor condicional, cf. Montolío Durán 1991.

${ }^{9}$ La noción de gobierno nacional implica, en este ensayo alberdiano, tanto lo político como lo económico. Desde la creación del Virreinato del Río de la Plata en 1776, el puerto de Buenos
} 
Luego, la reinstalacion del gobierno nacional argentino debe venir de una mano interesada, que es la de la Nacion, [?] al apoyo de una influencia indirecta de la Europa, como fué una influencia de ese genero la que en 1810 hizo caer en probecho local de $\mathrm{B}^{\mathrm{s}} \mathrm{A}^{\mathrm{s}}$. (Alberdi 1862: 1B16). ${ }^{10}$

Entre ambas cláusulas del período causal (entre paréntesis) de (11) no hay identidad de actante sujeto ni de tiempo y aspecto verbal, aunque sí hay identidad de lugar. Igual que en (11) la primera cláusula es un período condicional con su prótasis en pretérito perfecto simple y su apódosis en futuro, ambos en indicativo. Sin embargo, los períodos condicionales funcionan de manera diferente. El futuro de indicativo 'será' en (11) le otorga a la cláusula un valor de predicción muy diferente del valor hipotético del condicional 'constituiria' en (10).

Como sucedía en los otros dos ejemplos se rompe con el orden icónico de los hechos. La información nueva se presenta en la primera cláusula, específicamente en la apódosis (subrayada) y la información conocida está introducida por pues. Su carácter de conocida se ve reforzada por la expresión 'la experiencia ha demostrado'. Esta información es una explicación de la predicción que se ha realizado en la apódosis.

Como puede observarse, el grado de coherencia entre las cláusulas del período causal de (11) es bastante menor que en los casos anteriores. La causal está modificando a un verbo de lengua: Creo que no será Buenos Aires quien lo reponga, pues la esperiencia ha demostrado que el interes conque lo dispuso fue mas de su pueblo que el de la nacion.

El análisis de los distintos parámetros muestra que el ejemplo (9) es el que presenta mayor coherencia entre los conectados de los tres casos presentados más arriba. Esta coherencia se apoya en que Alberdi toma dos hechos reales y luego establece entre ellos una relación de causa-consecuencia. El caso (10), aunque en un grado menor que el anterior es muy coherente; presenta una relación parte-todo; hay una generalización y una conclusión. Alberdi se apoya en esa ley "universal"; no hay opinión del escritor como ocurre en la tercera. El ejemplo de (11) presenta la relación más laxa; la voz del autor está muy presente dado que hay una suposición, una predicción.

\footnotetext{
Aires concentra toda la importación y toda la exportación de productos argentinos. En la época colonial, los beneficios económicos que producía la aduana portuaria se repartían entre las distintas intendencias que componían el virreinato. Desde la revolución de 1810, Buenos Aires administró la renta de aduana que daba el puerto en su exclusivo beneficio puesto que no distribuía la riqueza del puerto entre las catorce provincias argentinas, aún cuando esta renta era el aporte fundamental del tesoro nacional y, por lo tanto, la base de la economía nacional y de las economías provinciales. El resultado de esto fue un paulatino empobrecimiento de las provincias y un enriquecimiento de Buenos Aires. Esta situación económica tenía su contrapartida política en los intentos de organización de un gobierno nacional unificado, lo que se manifiesta, principalmente, en las luchas entre unitarios y federales.

${ }^{10}$ Primer Borrador de la edición genética de De la anarquía, folio 16.
} 
Como puede observarse en estos tres ejemplos, la no iconicidad del orden de las cláusulas respecto del orden de los hechos y la presencia de distintas funciones retóricas en las dos cláusulas ubican estos períodos causales dentro de la relación de centro-periferia.

A continuación presentamos los resultados del análisis cuantitativo y cualitativo de todo el corpus analizado. En relación con el primer parámetro, continuidad tópica entre los conectados, el $63,67 \%$ de la totalidad de casos analizados no presenta identidad de actante sujeto entre los conectados, lo que indica que los períodos causales con pues tienden a manifestar baja continuidad tópica entre las cláusulas, lo que las acerca a la relación centro-periferia.

Con respecto a la distribución de la información, los datos obtenidos no muestran una tendencia clara. Si bien hay un 52,86\% de casos sobre la totalidad de los ejemplos analizados que presenta información nueva en una de las dos cláusulas (como suele ocurrir en la relación centro-periferia) y un 47,14\% que introduce información nueva en ambas cláusulas (propio de la coordinación), la diferencia es tan pequeña que no permite sacar conclusiones.

En cuanto a los dos últimos parámetros medidos, iconicidad del orden de las cláusulas y función retórica de los conectados, en consonancia con el primero (continuidad tópica entre los conectados), permiten incluir las cláusulas de pues en el ámbito de la relación centro-periferia, puesto que en el $100 \%$ sobre la totalidad de casos del corpus, los períodos causales con pues no respetan el orden icónico de los hechos y presentan distintas funciones retóricas en ambas cláusulas. Pues introduce explicaciones o justificaciones de lo dicho previamente, es decir, que la intención comunicativa de las cláusulas causales de pues es explicar o justificar mientras su respectiva cláusula-consecuencia realiza una aseveración (9), introduce una tesis (10) o propone una hipótesis $(11) \cdot{ }^{11}$

\section{CONCLUSIÓN}

De lo expuesto anteriormente puede concluirse que las cláusulas de pues presentan distintos grados de coherencia, en un continuum ordenado, pero no discreto. La relación sintáctica que las caracteriza es la de centro-periferia porque los períodos causa-consecuencia presentan dos hechos diferentes y es el escritor el que establece esa relación entre ellos. Se diferencian de la coordinación en que no se respeta el orden icónico de las cláusulas y en que cada cláusula presenta su propia función retórica. Se distinguen de la subordinación de actante en que

\footnotetext{
${ }^{11}$ Lejos de pretender realizar una tipología de las causas lingüísticas, podemos considerar que en nuestro corpus, basado en un ensayo argumentativo, hay tres tipos de relaciones entre la cláusula-causa y su respectiva cláusula-consecuencia que tienen su correlato en la intención comunicativa del escritor: a) Tesis + explicación $(88,64 \%)$, b) Hipótesis + explicación $(7,69 \%)$ y c) Consecuencia + causa $(3,85 \%)$.
} 
ninguna cláusula es parte de la otra, es decir, el hecho de una de ellas no funciona como un actante del hecho de la otra.

\section{BIBLIOGRAFÍA}

Alberdi, J.B. (1862), De la anarquía y sus dos causas principales y sus dos elementos necesarios en la República Argentina con motivo de su reorganización por Buenos Aires, Besanzon, París.

AlbeRDI, J.B. (1886-1887), Obras completas, Buenos Aires, Imp. Lit. y Enc. de “La Tribuna Nacional", 8 tomos.

AlARCOS, E. (1994), Gramática de la lengua española, Madrid, Espasa Calpe.

ALCINA FRANCH, J. y J.M. BLECUA (1991 [1975]), Gramática española, Barcelona, Ariel.

BELLO, A. (1972 [1847]), Gramática de la lengua castellana destinada al uso de los americanos. Con las Notas de Rufino Cuervo, Caracas, Ministerio de Educación.

Bentivoglio, P. (1983), "Topic continuity and discontinuity in discourse: a study of spoken Latin American Spanish", en Topic continuity in discourse: a quantitative cross-language study, Givón, T. (ed.), Amsterdam, Benjamins, 255-312.

BORZI, C. (1994), "La distribución de la información como proceso en fases”, Revista de Lingüística Teórica y Aplicada, 32, 5-27.

BorZI, C. (1998), "El papel del dinamismo comunicativo en el avance textual", Lingüística Española Actual, XX/2, 239-254.

BORZI, C. (1999), “La relación sintáctica de las causales con porque”, en "El Hispanismo al final del milenio", Actas del V Congreso Nacional de la AAH, C. Estofán, G. Gatti y S. Perrero (eds.), vol. 3. Córdoba, Comunicarte Editorial, 1547-1559.

BoRZI, C. (2001), "Coordinación y subordinación: zonas de una ojiva", en Volumen Homenaje a Ofelia Kovacci, E.N. de Arnoux y A. Di Tullio (eds.), Buenos Aires, EUDEBA, 91-112.

BorZI, C. (2010), Teóricos № 13 y 15. Cátedra: Gramática “C”, Facultad de Filosofía y Letras, Universidad de Buenos Aires.

CAMACHO, J. (1999[2000]), “La coordinación" en Gramática descriptiva de la lengua española, I. Bosque y V. Demonte (eds.), Vol. II., Madrid, Espasa Calpe, 2635-2694.

DANEŠ, F. (1974), "Functional Sentence Perspective and the Organization of a Text”, en Papers on Functional Sentence Perspective, Daneš, F. (ed.), La Haya/París, Mouton, 106-128.

Di Tullio, A. (1997), Manual de gramática del español, Buenos Aires, Edicial.

DIVER, W. (1995), "Theory", en Meaning as Explanation: Advances in Linguistic Sign Theory, E. Contini-Morava y B.S. Goldberg (eds.), Berlin, W. de Gruyter, 43-114.

GALÁN RODRíGUEZ, C. (2000 [1999]), “La subordinación causal y final”, en Gramática descriptiva de la lengua española, I. Bosque y V. Demonte (eds.), Vol. III. Madrid, Espasa Calpe, 3597-3641.

GILI GAYA, S. (2000[1943]), Curso superior de sintaxis española, Barcelona, Vox.

GIVÓN, T. (1980), Ute Reference Grammar, Colorado, UTE Press.

GOETHALs, P. (2002), Las conjunciones causales explicativas españolas 'como', 'ya que', 'pues' y 'porque'. Un estudio semiótico-lingüístico, Leuven, Peeters.

GutiÉRrez OrdóÑEz, S. (2000), “Causales”, Boletín de la RAE, Tomo 80, Cuaderno 279, 47-159. 
HOPPER, P.J. (1998), "Emergent Grammar and the A Priori Grammar Postulate", Linguistics in Context: Connective Observation and Understanding, D. Tannen (ed.), Ablex, Norwood, 5, 117-134.

LAPESA, R. (1978), "Sobre dos tipos de subordinación causal", en Estudios ofrecidos a Emilio Alarcos Llorach, tomo III, Oviedo, 173-205.

LAKOFF, G. (1987), Women, Fire and Dangerous Things, Chicago, University Press.

LANGACKER, R. (1987), Foundations of Cogntive Grammar. Theoretical Prerequisites, Grammar, Stanford, Stanford University Press.

LOIS, E. (2007), "La génesis textual de El crimen de la guerra", J.B. Alberdi, El crimen de la guerra. ed. crítico-genética presentada, establecida y anotada por E. Lois, Argentina, UNSAM Edita.

LÓPEZ GARCíA, A. (1994), Gramática del español 1. La oración compuesta, Madrid, Arco/libros.

MATTHIESSEN, C. y S. THOMPSON (1988), "The Structure of Discourse and 'Subordination'”, en Clause combining in grammar and discourse, J. Haiman y S. A. Thompson (eds.), Ámsterdam-Filadelfia, John Benjamins, 275-329.

MONTOlío DuRAN, E. (1991), "Acerca de las construcciones de gerundio con valor condicional", Anuari de Filologia, 14/F-2, 21-36.

MORÓN USANDIVARAS, M. (2012), “Una aproximación al uso de porque en el discurso alberdiano", en Estudios Cognitivos, Barbeito, V., Miñones, L. y Müller, G. (eds.), Editorial de la Facultad de Filosofía y Letras de la Universidad Nacional de Cuyo, Mendoza.

MORÓN USANDIVARAS, M. (2010), “Pues vs. porque en De la anarquía de Alberdi”, en La renovación de la palabra en el bicentenario de la Argentina. Los colores de la mirada lingüística, Castell, V. M. y Liliana Cubo se Severino (eds.), Mendoza, Editorial de la Facultad de Filosofía y Letras de la Universidad Nacional de Cuyo, 883-888.

Moure, T. (1994), “La Teoría de los Prototipos y su aplicación en Gramática”, Contextos, XII, 167-219.

PORROCHE BALLESTEROS, M. (2002), "Las llamadas conjunciones como elementos de conexión en el español conversacional: pues/pero", Círculo de Lingüística Aplicada a la Comunicación 9, 35-54.

PORTOLÉS, J. (1989), “El conector argumentativo pues”, Dicenda, 8, 117-133.

ReAl ACADEMia EsPañola (1931), Gramática de la lengua española, Madrid, Espasa Calpe.

REAL ACADEMIA EsPAÑOla (1981 [1973]), Esbozo de una nueva gramática española, Madrid, Espasa Calpe.

Real Academia EsPañola (2009), Nueva Gramática de la lengua Española, Madrid, Espasa.

Rojo, G. (1978), Cláusulas y oraciones, Vigo, Universidad de Santiago de Compostela.

Rosch, E. (1978), "Principles of Categorization", en Cognition and categorization, Rosch E., Lloyd B.B. (eds.), Hillsdale, 27-48.

SECO, M. (1999), Gramática esencial del español, Madrid, Espasa-Calpe.

VERSTRAETE, J.C. (2007), Rethinking the Coordinate-Subordinate Dichotomy. Interpersonal Grammar and the Analysis of Adverbial Clauses in English, Berlin-New York, Mouton de Gruyter. 